OBETS. Revista de Ciencias Sociales

Vol. 10, n. ${ }^{\circ} 1,2015$, pp. 127-158

ISSN: 1989-1385

DOI: 10.14198/OBETS2015.10.1.05

\title{
LA EMPRESA SOCIAL EN ESPAÑA Y EN ITALIA DURANTE LA CRISIS ¿UN LABORATORIO DE INNOVACIÓN ECONÓMICA Y SOCIAL? ${ }^{1}$ SOCIAL ENTERPRISE IN SPAIN AND ITALY DURING THE CRISIS. A LABORATORY FOR ECONOMIC AND SOCIAL INNOVATION?
}

\author{
Andrea Pirni \\ Departamento de Ciencias Políticas y Sociología \\ Universidad de Genova, Italia \\ andrea.pirni@unige.it \\ Luca Raffini \\ Departamento de Ciencias Políticas y Sociología \\ Universidad de Genova, Italia \\ lucaraffini@gmail.com
}

\section{Resumen}

En este articulo analizamos el desarrollo de empresa social en España e Italia en el marco de la crisis económica y social, en términos de difusión y marco juridico. De esta manera, definimos los confines del "ecosistema" de la empresa social en los dos países e identificamos elementos comunes y especifidades. La hipótesis es que la empresa social representa una herramienta de generación

\footnotetext{
${ }^{1}$ El artículo parte del estímulo de las reflexiones teóricas y de los análisis empíricos llevados a cabo en el ámbito de la investigación "Giovani, volontariato e impresa sociale. Il Terzo settore toscano come laboratorio di nuovi modelli di sviluppo economico e sociale", patrocinada por Cesvot (Centro Servizi per il Volontariato Toscana) y llevada a cabo por Ceuriss (Centro Europeo di Ricerche e Studi Sociali). La investigación, realizada en collaboración con Cesvot, se ha centrado en el análisis del "matching" entre voluntariado y empresa social en Toscana. En esta contribución, en cambio, comparamos el contexto italiano y el español, y reflexionamos sobre las perspectivas de desarrollo de la empresa social en los dos países. El articulo es fruto de una reflexión compartida por los autores. Andrea Pirni redactó los apartados 1 y 2; Luca Raffini escribió los apartados 3, 4, 5 y 6. Los autores agradecen a Clemente Penalva por su revisión meticulosa del texto en español.
} 
de respuestas proactivas a la crisis, impulsando trayectorias de innovación económica y social, y contribuyendo a un modelo de desarrollo económica y socialmente sostenible. La innovación surge de la capacidad de las empresas sociales de generar respuestas innovativas a demandas emergentes, de su capacidad de crear al mismo tiempo valor social y económico, de satisfacer necesidades individuales y colectivas, de activar dinamicas de cambio de medio y largo plazo, de estimular dinamicas de emprendimiento, de empoderamiento y de valorización en el territorio. Sin embargo, el carácter innovador de la empresa social no surge simplemente de una empresarializacción del Tercer Sector tradicional, y mucho menos como consecuencia de la transferencia de servicios fundamentales del estado a asociaciones, cooperativas y empresas sociales, si con eso se persigue el simple objetivo de reducción de los gastos públicos. Al contrario, detrás de la retórica de la innovación social se puedan esconder proyectos de reducción de los gastos de servicios a través de la reducción de los salarios y de la cualidad de los servicios. El artículo, a partir de la comparación de la difusión del fenómeno y de las perspectivas de desarrollo en España y en Italia, termina con una reflexión crítica sobre las luces y sombras, los riesgos y las oportunidades, relacionados con la difusión de la empresa social, o sea, de la integración de la acción solidaria y la acción económica en prácticas que son al mismo tiempo empresariales y con finalidades sociales.

Palabras clave: Empresa social; crisis; comparación España-Italia; innovación social; Tercer Sector

\section{Abstract}

The contribution explores the development of social enterprises in Spain and Italy in the framework of the economic and social crisis. Comparing the spread of the phenomena and its legal framework, we define the boundaries of the "ecosystem" of social enterprises in the two countries, identifying commonalities and specificities. The hypothesis is that the social enterprise represents a proactive tool for generating responses to the crisis, promoting economic and social trajectories of innovation and contributing to a sustainable development model. Innovation comes from the power of social enterprises to generate innovative responses to emerging demands and from the ability to create both social and economic value, to meet individual and collective spheres, enabling paths of change in the medium and in the long term and promoting the empowerment processes in the local dimension. Yet, the innovative character of the social enterprise does not merely arise from the externalization of social services from the public to the third sector, in order to reduce public expenditure. Instead, behind the rhetoric of social innovation it can hide projects to reduce public service through cutting down on wages and the quality of services. The article compares the presence and prospects of development of the phenomenon in Italy and Spain and, finally, offers a critical reflection on the risks and opportunities related to the spread of the social enterprise, as it is characterized by a novel integration between solidarity action and economic action, in entrepreneurial practices serving a social purpose.

Keywords: Social entreprise; crisis, Italy-Spain comparison; social innovation; third sector 


\section{Extended abstract}

The persistent economic crisis fosters structural changes in the relationship between public sector, private sector and non profit. Change in welfare systems and growth and pluralization of social needs challenge non profit organizations. These are required to solve new social needs, which have no solutions either by the public sector or by the market. The expansion of social needs spurs a quantitative and a qualitative transformation of non-profit organizations. NGOs are experiencing a process of professionalization, as they are increasingly engaged in the production of services, in order to provide innovative and effective responsens to emerging social needs. The third sector has for long time been defined in a residual manner, as the intermediate realm between state and market. Nowadays it becomes a strategic area in which new combinations of "solidarity actions" and "economic action", are experimented. Third sector organizations do not deals with individuals as users or customers. Rather, they include them actively in the implementation and delivery of services, promoting self-activation dynamics. In this context of change, the social enteprise acquires an increasing relevance, as it acts across the shifting boundaries between economic action and solidarity action. We can define social enterprise as the business dimension of the social economy, or the most ethical way to exercise an entrepreneurial role. The social enterprise represents an hybridization between languages and forms of action transforming both economic action and social action. This type of hybridization is not conducive to an "absorption" or "submission" of each other, rather to the making of a new form of action. Social enteprise is not intended to make profit. On the contrary, it is a mean to achieve social purpose. There is not a trade-off between entrepreneurial approach and social orientation, as entrepreneurial approach is the key to enhance social goals and rootness in society is an assett to achieve economic sustainability. Social entreprises, according to the European "social business initiative", are leading actors in the creation of a innovative social and economic model, based on growth and cohesion and able to combine job creation and innovative solutions to social needs. This kind of challenge is even more relevant for Southern European countries, more affected by the economic and social crisis. Here the spread of social enteprise can encourage and support process of social innovation: social enterprise lay on the basis of a new development strategy, based on the valorization of local resources and in the promotion of shared project of collective growth.

This articles analyzes the development of social enterprise in two countries particularly affected by the crisis, Italy and Spain. The hypothesis is that the spread of social enterprise may represent a proactive tool to project a way-out to the crisis, promoting trajectories of economic and social innovation. Several reasons contribute to place the two Mediterranean countries at the forefront in the promotion of social enterprise, as a key actor in triggering processes of social innovation. Along with Britain, Italy and Spain are among the European countries where the "dismantling" of the welfare state is more advanced, leaving room to a greater role for non profit organizations in the provision of social 
service. Further, Italy and Spain are among the European countries where social economy is more consolidated. In Spain more than 1.200.000 employees in voluntary organizations and in cooperatives are estimated, representing around $7 \%$ of all employees. In Italy the employees in the social economy are more than 2.200.000: almost $10 \%$ of total employees work in the social economy. In both countries social economy revealed to act countercyclically, substaining economic growth and job-creation, in time of crisis. The rate of growth of social economy, from 2003 to 2010, is 43,5\% in Spain and $66,7 \%$ in Italy. However, not all organizations active in the field of social economy can be labelled as social enterprise. The boundaries of the social economy are both wider and narrower than those of social enteprise. Adopting the traditional European approach, social enterprise only includes the most market-oriented segment of social economy, and can be can hence be seen as a subset of the latter. On the other hand, according to a wider approach, typical of the anglosaxon tradition, we can label as social enterprise also organizations that do not belong to the tradition of the social economy, and which operates in different fields of activities, i.e. business corporations. According to this approach the characterization as social enteprise is given by the non profit dimension and by the social goal of business, more than by legal status or field of activities. The definition of social enterprise, in this "thick" definition, embraces all kind of organization which combine entrepreneural approach and social orientation. From these premises, the article outlines the ecosystem of social enterprise in the two countries, namely the organizations which fall in the realm of "ex lege social enterprise" (organizations acting under the umbrella of a specific law on social enteprise), in the realm of "de facto social enterprises" (organizations acting as social enterprise, even if non explicity framed as social enteprise) and in the realm of "potential social enterprise" (including organizations that have at least some of the features that define social enterprises and those who aspire to become social enteprise). Italy, because of the coexistence of social cooperatives (de facto social enteprises), social enteprises ex lege and a plurality of third sector organizations active in the production of service (potential social enteprise), is characterized by a wide and varied, as well as fragmented, ecosystem. Finally, the article explore the potenciality of development of social enterprise in both countries. The social enterprise is defined by a difficult and unstable balance between social dimension and business dimension. The innovative value of the social enterprise, as a mean to combine economic and social values and to integrate individual and collective concerns, depends on the ability to maintain and strengthen this equlibrium, so that the social goal will not compromise the entrepreneurial approach and the entrepreneurial orientation will not corrupt the social inspiration. Social enterprise can act as a leading actor in the making of a new models of society, based upon economically and socially sustainable development, as it is stated by Europe2020 declaration. This achievement depends on the ability, on European, national and local level, to foster a favourable ecosystem, promoting social innovation practices in different fields, including ICT'S, and not narrowing the field of action of 
social enteprise within the traditional boundaries of the social economy, namely in the field of social and care services and in the work integration of disadvantaged people. The expansion in the form and in the scope of social enteprise represent an strategy for the promotion of social innovation and for the achievement of a model of social and economic sustainable growth, conducive to a "civilization of economy". However, this structural trasformation of social enterprise, via the opening of its borders, involve risks, besides opportunities. The social enteprise can represent a possible proactive response to social and economic crisis, combining job creation and contribution to social innovation, if it succeeds in virtuously combining economic and solidarity action and in movilizing material and immaterials resources in the creation of shared values. On the contrary, if social enterprise merely becomes a means for reducing wages and quality of services through externalization of basic service, it would not fulfill its promise of social innovation.

\section{INTRODUCCIÓN. LA CRISIS Y EL DESAFÍO DE LA EMPRESA SOCIAL: UNA COMPARACIÓN ENTRE ESPAÑA E ITALIA}

La persistente crisis económica ha provocado cambios estructurales en la relación entre el Tercer Sector, las instituciones políticas y económicas y el mercado del trabajo. Las transformaciones de los sistemas de bienestar, y el crecimiento y la pluralización de las necesidades sociales han ampliado el ámbito de las necesidades que no encuentran respuesta ni en el sector público ni en el sector privado. Eso ocurre en un contexto de crisis interna del modelo neoliberal, en el cual, junto a los recortes en el gasto público hay que añadir la incapacidad, por una parte creciente de la población, de comprar los servicios en el mercado, debido al empeoramiento de su condición económica y social. Como resultado, se desarrollan experiencias de resiliencia y de economía alternativa (Forno, 2014). Es dentro de este contexto de cambio donde podemos analizar las dinámicas de transformación del Tercer Sector, y, más especificamente, el fenómeno de la empresa social.

La expansión de las necesidades sociales alimenta una transformación cuantitativa y cualitativa de las organizaciones sin ánimo de lucro que, cada vez más, se han embarcado en un proceso de profesionalización, centrándose en una producción continua de servicios que ofrece respuestas a las necesidades sociales emergentes. El aumento y la diversificación de las demandas y la paralela reducción de la intervención pública, representan un desafio para el Tercer Sector, que se ve llamado a desempeñar un papel de integración/sustitución y, al mismo tiempo, de estímulo-anticipación de la intervención estatal. La transición de un modelo tradicional de "welfare state" a lo que ha sido llamado un modelo de "welfare mix" (Ascoli y Ranci, 2003), de "welfare society" (Donati y Colozzi, 2005), o hasta "segundo welfare" (Ferrera y Maino, 2013) ha sido 
analizado como una oportunidad de alcanzar un equlibrio óptimo entre equidad y eficacia, promoviendo el desarrollo de interacciones virtuosas entre iniciativa pública, privada y del Tercer Sector, y como actuación del principio de subsidiariedad. Al Tercer Sector, particularmente, se le atribuye una mayor capacidad para responder a las necesidades de las personas y para promover caminos de empoderamiento y de auto-activación, que parecen más dificiles de cumplir en el paradigma tradicional de la intervención pública, más centrada en la producción de respuestas estandarizadas y burocráticas. Ya no simplemente definido de manera residual, como un ámbito intermedio entre estado y mercado, el Tercer Sector se vuelve un lugar estrategico en el que se experimentan nuevas combinaciones entre "acción solidaria" y "acción económica". Lo que esperamos del Tercer Sector no es simplemente que consiga hacer lo que también pueden hacer el público y el privado pero de manera más barata, sino que lo haga de manera diferente, promoviendo dinámicas de auto-activación de los beneficiarios.

Es dentro de este proceso de cambio donde adquiere centralidad el concepto de empresa social, que define un verdadero híbrido organizativo y conceptual, que combina de manera innovadora elementos propios de ámbitos de acción diferentes y -aparentemente- incompatibles. Podemos definir la empresa social como la dimensión más empresarial del Tercer Sector, o, especulativamente, como la manera más ética de ejercer un papel empresarial. La empresa social nace de una hibridación entre plantamientos y formas de acción que transforman tanto la acción económica como la acción social, no en la dirección de una "absorción" o "sumisión" de una a la otra, sino en la dirección de construir una nueva forma de acción, que es empresarial para conseguir su finalidad social y que puede llevar a cabo su finalidad social porque es empresarial.

Sin embargo, ¿la empresa social cumple efectivamente con su promesa de integración virtuosa entre acción solidaria y acción económica y de volver la primera más eficaz y la segunda más ética? ¿O detrás de la retórica de la empresa social se oculta un mero proceso de profesionalización y de empresarialización del Tercer Sector? Este tipo de hibridación puede conllevar efectivamente críticas, en el momento que, según un enfoque crítico, favorece una privatización de los servicios sociales, una reducción de los derechos y, por esta vía, una disminución de la universalidad del estado de bienestar, además de su calidad (tanto referida a los destinatarios de los servicios, como a la calidad del trabajo). Además, la transferencia de servicios sociales del público al privado social o al Tercer Sector, puede ser simplemente perseguida como medida de reducción de los gastos en la provisión de los servicios existentes y no para la experimentación de nuevos ámbitos de actividad y nuevas modalidades de actuación y para la implementación de nuevos derechos. 
Al contrario, la superación de los confines tradicionales entre los ámbitos de actividad puede fomentar el desarrollo de trayectorias de innovación social y sentar las bases de un nuevo modelo económico y social, orientado hacia criterios de sostenibilidad en ambas dimensiones; todo ello si se enmarca en un contexto de verdadera redefinición crítica del papel social del emprendimiento, que ve en el Tercer Sector un ámbito privilegiado de experimentación. Esto, debido a la flexibilidad que lo caracteriza, se configura como un laboratorio de innovación social y económica. Adoptando, precisamente, esta perspectiva, la Comisión Europea ha implementado la "Social Business Initiative", para promover el desarrollo del emprendimiento social en Europa. Objetivo de la iniciativa europea es construir un ecosistema propicio para el desarrollo del emprendimiento social (OCDE/European Commission, 2013), mejorando el accesso a la financiación, mejorando el entorno jurídico, mejorarando la visibilidad de esas organizaciones y promoviendo la difusión de las mejores prácticas.

La implementación de políticas proactivas para promover la empresa social se explica por la conciencia, por parte de los responsables políticos europeos, de que ésta pueda no solo contribuir a reducir el gasto público en políticas sociales y a responder más eficazmente a las necesidades plurales de sociedades complejas, sino también a generar impactos positivos en la dimension social, ambiental y económica, sentando las bases para un nuevo modelo de sociedad que permita salir proactivamente de la crisis, generando valor económico y social. La Social Business Initiative, desde esta perspectiva, está en plena sintonía con la estrategia Europe2020, que califica las orientaciones que deben guiar los procesos ecónomicos y sociales para salir de la crisis, y establecer un nuevo modelo económico y social europeo. Las prioridades son el crecimiento "inteligente" (basado en el conocimiento y en la innovación, además del uso de la red), "sostenible" (que consigua conciliar competividad y crecimiento económico con la defensa de los recursos ambientales y sociales) e "integrador" (que sepa favorecer la creación de trabajo, la adquisición de cualificaciones y la equidad social). De esta manera, se confirma el distintivo objetivo de la precedente estrategia de Lisboa, o sea, reafirmar un modelo social europeo, y hacer de la UE la economía más competitiva del mundo basada en el conocimiento. A esos objetivos se hace referencia directa en la Iniciativa Europea sobre la empresa social, en la que se afirma que

el objetivo principal de las empresas sociales es generar un impacto significativo sobre la sociedad, el medio ambiente y la comunidad local. Al responder mediante la innovación social a necesidades aún no satisfechas, las empresas sociales forman parte de un crecimiento inteligente. Por ejemplo, muchas 
empresas sociales ponen gran empeño en alentar a los trabajadores a formarse y actualizar sus conocimientos. Al tener en cuenta su impacto medioambiental y mediante su visión a largo plazo, generan un crecimiento sostenible. Por ejemplo, las empresas sociales desarrollan con frecuencia soluciones eficientes para reducir las emisiones y los residuos u optimizar los recursos naturales. Además, al poner especial énfasis en las personas y la cohesión social, las empresas sociales son el núcleo de un crecimiento inclusivo: crean puestos de trabajo sostenibles para las mujeres, los jóvenes y las personas mayores. En otras palabras, su principal razón de ser es organizar transformaciones sociales y económicas que contribuyen a los objetivos de la Estrategia Europa 2020 (Comisión Europea, 2014).

Paradójicamente, podemos afirmar que si la crisis financiera y productiva ha frenado la realización de los objetivos de la estrategia de Lisboa, al mismo tiempo ha confirmado la urgencia de pensar y poner en marcha un nuevo modelo económico y social, capaz de combinar desarrollo económico y cohesión social, de crear oportunidades de trabajo y generar respuestas a las necesidades sociales emergentes. Es un desafío que parece aún más urgente en los países más afectados por la crisis económica, y en particular en los países de la Europa mediterránea, donde ésta se ha convertido en una crisis social y política que amenaza con generar un círculo vicioso. Los países de la Europa mediterránea sufren, más que otros países europeos, la caída de la producción y el aumento del desempleo, el aumento del riesgo pobreza y de formas de marginalidad y de exclusión social y, paralelamente, los efectos de la reducción de los gastos en el estado de bienestar, y por tanto, de la capacidad de responder a las crecientes demandas de los ciudadanos. Como consecuencia, la crisis económica alimenta la desigualdad y la reducción de la cohesión social. En ese contexto, el desarrollo del emprendimiento social puede favorecer procesos de innovación social, que consigan integrar la creación de empleo para los jóvenes o para quien haya perdido su trabajo, y generar respuestas innovativas a las necesidadas emergentes que no encuentran más, o que todavía no encuentran respuestas por parte del estado y del mercado; y puede sentar las bases para una estrategia de desarrollo que pasa por la valorización de los contextos locales, movilizando los recursos del territorio en proyectos compartidos de crecimiento.

En este artículo analizamos las persectivas de desarrollo de la empresa social, en dos países particularmente afectados por la crisis, España y Italia. La hipótesis es que la empresa social representa una herramienta de generación de respuestas proactivas a la crisis, impulsando trayectorias de innovación económica y social. Italia y España, junto con Reino Unido, son entre los países europeos en los que el "desmantelamiento" del estado de bienestar está más 
avanzado, y al mismo tiempo entre los países en que existe la mayor perspectiva de desarrollo de la economía social (Jiménez Escobar, Morales Gutiérrez, 2011: 46). Sin embargo, la presencia actual de este tipo de organizaciones es muy alta en Reino Unido, con una tasa entre las mayores en Europa y mucho menor en España, donde está muy por debajo del promedio europeo. En Italia hay una situación intermedia, pero con un predominio de empresas sociales consolidadas, mientras que en España hay una prevalencia de empresas jóvenes. Eso significa que en los dos países hay una fuerte potencialidad de desarrollo de la empresa social, considerándola un elemento más que caracteriza a España y a Italia. Estos países, diferentemente de Reino Unido, están afectados por los efectos de la crisis económica en el mercado del trabajo. Como consecuencia, en estos países, el debate sobre las perspectivas de desarrollo de la empresa social, además que sobre la necesidad de reinventar el modelo de estado de bienestar, se focaliza mucho sobre su capacidad de actuar como generadora de empleo y de innovación social. A partir de este enmarcamiento, analizaremos el estado de desarrollo de la empresa social en los dos países, compararemos la presencia numérica de organizaciones que pueden ser definidas como tal y sus características, estudiaremos el marco juridico nacional e investigaremos el debate nacional sobre Tercer Sector y emprendimiento social. El objetivo es comparar el nivel actual y las perspectivas de desarrollo del "ecosistema" de la empresa social en los dos países, identificar elementos comunes y de diversidad, y evaluar en qué manera, en la práctica, el desarrollo de la empresa social puede representar una respuesta proactiva a la crisis económica $\mathrm{o}$, al contrario, como detrás de la retórica de la innovación social se puedan esconder proyectos de reducción de los gastos de servicios a través de la reducción de los salarios y de la calidad de los servicios.

\section{NUEVAS RELACIONES ENTRE ACCIÓN PÚBLICA, ACCIÓN ECONÓMICA Y ACCIÓN SOCIAL}

Los estados europeos son caracterizados, según la conocida tipología de EspingAnderson (1990), como modelos diferentes de Estado de bienestar, en referencia a su origen, su trayectoria de desarrollo, su relación con los ciudadanos, y, finalmente, por el tipo de relación que hay entre actores públicos, privados y del Tercer Sector.

El modelo socialdemócrata, típico de los países del Norte Europa, se centra en el Estado como proveedor de servicios de naturaleza universal para la ciudadanía. En estos países las organizaciones del Tercer Sector se han dedicado, de manera casi exclusiva, a realizar actividades de advocacy, y no han actuado como dispensadores de servicios. El papel del Tercer Sector ha sido tradicionalmente 
más relevante en los países de Europa Central, caracterizados por un modelo de welfare de tipo conservador, fundado sobre el mutualismo y el corporativismo. En Austria, Alemania y Países Bajos, el Tercer Sector es una columna del sistema de welfare. Las organizaciones "non profit" han seguido un proceso de profesionalización y han adquirido un perfil market-oriented, aunque manteniendo una estrecha relación con los actores públicos. También en Bélgica y en Francia el papel de las organizaciones del Tercer Sector en la producción de servicios ha sido históricamente muy relevante, y las organizaciones, de manera mayoritaria, están subvencionados por el público. En estos países, las organizaciones sin ánimo de lucro definen el ámbito de la economía social, concepto de origen francés, que describe un ámbito intermedio entre los sectores público y privado. En comparación con los países de habla alemana, en estos países el concepto de empresa social es más ampliamente reconocido, debido a la histórica presencia de las cooperativas, que representan la dimensión más empresarial de la economía social. El Reino Unido se desmarca de la Europa Continental debido a la adopción de un modelo de bienestar residual, de carácter liberal. Aquí, el papel de lo público en la prestación de servicios se reduce fuertemente a favor del sector privado y del "non profit", que no sólo se financia con fondos públicos, sino también con recursos externos. Las organizaciones benéficas juegan un papel clave en la integración de la intervención pública. La centralidad del non profit en la prestación de servicios se encuentra ulteriormente fortalecida en los últimos años, gracias a iniciativas y proyectos como la Big Society y la Big Society Bank, cuyo objetivo es promover y financiar creación de empresas sociales.

Finalmente, el modelo mediterráneo, que incluye a Italia y España, se caracteriza por un desarrollo tardío, además de parcial, del Estado de bienestar, que tradicionalmente delegó muchas funciones, que en otros países son gestionados por lo público, a las familias. Al mismo tiempo, la naturaleza no universalista y las lagunas que caracterizan el Estado de bienestar, ha favorecido que jueguen un papel central las organizaciones sin ánimo de lucro, especialmente las relacionados con la Iglesia, que han llevado a cabo, históricamente, una serie de funciones complementarias y subrogatorias de la intervención pública, persiguiendo un enfoque caritativo, más que empresarial. En Italia, en los años setenta, se toma conciencia de que la transformación de la sociedad, que se vuelve cada vez más compleja, crea demandas diferenciadas y plurales a las que el Estado de bienestar no consigue dar respuesta. En esta fase, al lado de las tradicionales organizaciones de tipo "caritativas", surgen organizaciones que siguen un enfoque diferente, más centrado en la producción de servicios y en la promoción del principio de auto-organización de la sociedad, y que persi- 
guen un equilibrio entre eficacia de la intervención, economicidad y equidad. La profesionalización del Tercer Sector es hoy un fenómeno muy avanzado en Grecia, España, Italia y Portugal. En estos países, como veremos a continuación, el concepto de empresa social tiene un nivel de difusión diferente. En cambio, el concepto más amplio de economía social, goza de un alto nivel de aceptación (Monzón y Chaves, 2012). El modelo mediterráneo es, finalmente, uno de los más afectados por la re-estructuración/reducción de la intervención pública. Es un proceso que ha tenido un clímax anterior a la crisis que comenzó en 2008, y que ha alcanzado niveles máximos en Grecia, donde los servicios públicos, hasta los fundamentales, han sufrido una reducción drástica. La reestructuración del Estado de bienestar, que se desarrolló en el marco de un contexto de necesidades crecientes y cada vez más diversificadas, ha estimulado nuevamente una reorientación del papel del Tercer Sector, que ha abierto nuevas áreas de intervención. Eso explica porqué los países de la Europa Mediterránea, junto con el Reino Unido, son aquellos en los que el proceso de transformación del Tercer Sector más ha avanzado. Los países del Mediterráneo representan un terreno fértil para el desarrollo de proyectos de empresa social y de dinámicas de innovación social. En los dos países, efectivamente, el tejido de organizaciones activas en el ámbito de la economía social se está fortaleciendo y ampliando en el contexto de crisis, relevando una capacidad de responder a la misma de una manera anti-ciclíca. Ésta, en los dos países, ha sufrido menos los efectos de la crisis en comparación con los actores y los ámbitos económicos, ha seguido ampliando el número de puestos de trabajo y, hoy en día, parece estar más equipada para salir antes y mejor de la crisis (Triper, 2013; Venturi y Zandonai, 2014). En los dos países, el sector más dinámico e innovador de la economía social es el del emprendimiento social, cuyos confines no corresponden directamente con los confines de la economía social, incluyendo, en su interior, solo los actores que actúan de manera más claramente empresarial, tienen un número de asalariados superior al de voluntarios y venden sus servicios/productos en el mercado. Paralelamente al proceso de profesionalización y empresarialización del Tercer Sector, surgen nuevos proyectos de emprendimiento social, que no tienen raíces en el tradicional mundo de la economía social, y que, al contrario, representan un nuevo modo, sobre todo por parte de los jóvenes, de construir proyectos empresariales innovadores.

Debido a su carácter híbrido e indefinido, a su relativa novedad, a la escasa difusión del término, si lo comparamos con la difusión y aceptación de términos como "non profit" o "Tercer Sector", el ámbito de delimitación de la empresa social, en países como España y Italia está todavía indefinido. De manera 
particular, lo que no está claro es su delimitación con respecto a las organizaciones más tradicionales de la economía social, que a menudo actúan como empresa social a partir de las organizaciones de voluntariado. Esto significa que para analizar la difusión efectiva del fenómeno hay que sumar una pluralidad de prácticas, con estatus jurídico y denominación diferente, que comparten todas, o al menos, las principales características que definen la empresa social. El resultado de este tipo de enfoque será la individuación de una delimitación "amplia" del fenómeno -que cubre también un ámbito que podemos llamar de empresa social potencial- y de una delimitación estrecha del fenómeno, que incluye aquellas organizaciones que, a pesar de su estatus jurídico, cumplen con todas las características de la empresa social.

Sin duda, la difusión pública del concepto es mayor en Italia, donde existe una ley sobre la empresa social, aprobada en el 2005, y ha sido recientemente aprobada un decreto ley de reforma del Tercer Sector, entre cuyos objetivos está promover ulteriormente el desarrollo de la empresa social. En España, al contrario, la normativa no se refiere directamente al concepto de empresa social, sino al concepto más amplio y general de economía social (Ley 5/2011). No obstante, también en España aumentan las experiencias de empresa social, de facto o potencial, o sea, de organizaciones que actúan de acuerdo con las características y los planteamientos de la empresa social y hay entidades que fomentan su difusión. También hay un debate sobre la oportunidad de integrar la Ley 5/2011 sobre la economía social en una normativa más especifica sobre la empresa social.

\section{LA EMPRESA SOCIAL EN ITALIA Y EN ESPAÑA EN EL CONTEXTO EUROPEO}

Borzaga y Fazzi definen las empresas sociales como "organizaciones productivas que de manera explícita no persiguen lucrarse, sino la satisfacción de las necesidades de la gente y de la comunidad, y por lo tanto no distribuyen utilidades o lo hacen de manera limitada y son controlados por los mismos beneficiarios" (Borzaga y Fazzi, 2011: 16). De acuerdo con la definición, elaborada por la red de investigación Europea Emes (Borzaga y Defourny, 2001; Defourny y Nyssens, 2010), la empresa social debe ser ante todo una actividad empresarial. Como tal produce de forma continua, y no de manera marginal o intermitente, bienes y servicios y actúa en el mercado con un nivel significativo de asunción de riesgos económicos. Finalmente, hay una presencia mayoritaria de trabajadores asalariados. La dimensión social se cumple si hay una finalidad social explícita y constitutiva y si hay procesos de gobernanza democrática en los que el poder de decisión no es proporcional a la cantidad de 
capital, sino que se conforma según el principio de "una cabeza, un voto". En fin, no hay redistribución de las utilidades. Éstas deben ser reinvertidas o utilizadas para cumplir con el objetivo social de la empresa. Es integrando estas características que la empresa social, en Europa, actúa como un actor protagonista en el amito de la economía social, que en la tradición europea representa un "polo de utilidad social" (CIRIEC, 2012: 7), que surge entre el sector público y el sector privado. Las empresas sociales pueden ser conceptualizadas como el componente "market oriented" del Tercer Sector; mientras las organizaciones de voluntariado y fundaciones constituyen el componente "non market oriented". Siguiendo un enfoque parcialmente alternativo, el proceso de hibridación culminará creando un nuevo ámbito, distinto al de la economía de mercado y también del Tercer Sector, o sea, un Cuarto Sector (Jiménez Escobar, Morales Gutiérrez, 2011), entre cuyas características principales están las finalidades sociales, el enfoque empresarial, la propiedad inclusiva, la gestión colectiva, una justa retribución de los trabajadores, y la responsabilidad social y ambiental. Sin embargo, debido a la diversidad de los contextos nacionales y a las diferencias entre las normativas, es difícil decir con claridad cuánto está desarrollado el fenómeno a nivel europeo y qué margen de ampliación tiene. Circunscribiendo el campo a las organizaciones sociales que cumplen con todos los requisitos establecidos por la definición de empresa social de EMES, y que ha sido aceptada por la Comisión Europea (2014), se estima que el impacto de la empresa social en el total de los negocios no supera, en la UE28, el $1 \%$, aunque no resulta posible reconstruir datos exactos para todos los países, dada la diferencia en las leyes y en los métodos de recolección de datos. Es un valor que parece todavía muy bajo, si lo contrastamos con las perspectivas de desarrollo de la empresa social en los próximos años, debido al creciente interés hacia el fenómeno, ya sea en el mundo de la investigación ya sea en la política, que se ha traducido, en la principal dimensión, en la consolidación de redes de investigaciones nacionales e internacionales sobre Tercer Sector y empresa social, y en la difusión de leyes especificas que definen, regulan y promuevan la ampliación de la economía social y la difusión de la empresa social. Gem (2009), construye los datos nacionales sobre los resultados de una muestra que analiza las percepciones subjetivas de los trabajadores. Según la encuesta Gem, en Finlandia las empresas sociales emplean al 5,1\% de los trabajadores y en el Reino Unido el 4,2\%. En Bélgica y en Francia el porcentaje baja al 3\% y al 2,6\%. En Italia el dato es ligeramente inferior (2,5\%), mientras que el dato de España pone el país en el nivel más bajo de la parrilla europea (0,9\%). En España, más que en Italia y en otros piases como el Reino Unido, donde la presencia de empresas sociales está consolidada, hay una alta incidencia de empresas sociales "jóvenes" (el 60\%), mientras en Italia éstas representan el 49\% (se con- 
sideran empresas sociales jóvenes las que tienen menos de tres años de actividad, ibídem). Los datos recogidos por GEM, sin embargo, reflejan una definición estrecha de empresa social. Si ampliamos la perspectiva hasta analizar todo el sector, más amplio, de la economía social, encontramos datos muy interesantes que nos sugieren que, a lado del ámbito de la empresa social rígidamente definida, hay un amplio ámbito de empresa social potencial, y que un reciente informe de la Comisión Europea ha definido como el "ecosistema" de la empresa social (Comisión Europea, 2015a), cuyos principales actores son las organizaciones "tradicionales" del Tercer Sector, que de alguna maniera participan en actividades profesionales, actúan en el mercado e integran a los trabajadores voluntarios remunerados. Según la investigación llevada a cabo por Monzón y Chaves (2012), la incidencia de empleados en el amplio mundo de la economía social, en toda Europa, es muy alta, también en países en los que la empresa social, definida de manera estrecha, no parece muy presente.

En Italia, en 2009-2010, hay 1.128.381 empleados en cooperativas, a los que se suman 1.099.629 empleados en asociaciones. En España los empleados en cooperativas son 646.397, los empleados en mutuas son 2.700, y los que trabajan en asociaciones son 588.056. Eso significa que en los dos países el porcentaje de empleados en la economía social, respecto al total de los empleados, es muy alto: el 9,7\% en Italia y el 6,7\% en España. Son datos inferiores a los de Suecia, Bélgica y Países Bajos, que superan el 10\%, pero superiores al dato de países como Reino Unido (5,6\%). Es particularmente interesante analizar la tasa de crecimiento de empleados en la economía social. Del 2002-2003 al 2009-2010, el aumento en Italia ha sido del 66,7\% y en España del 42,5\%. Entre los otros países europeos, los hay donde el aumento ha sido aún más fuerte, hasta el 146,6\%; pero también hay países con una fuerte tradición de economía social en los que el dato ha subido mucho menos (Francia: 16,8\%) o incluso se ha reducido (Reino Unido: -4,6\%). Eso confirma que, en los dos países, el ámbito potencial de desarrollo de la empresa social es muy amplio.

Tabla 1. La economía social en España y en Italia

\begin{tabular}{l|c|c|c|c}
\hline & \multicolumn{2}{|c|}{$\begin{array}{c}\text { La economía social: } \\
\mathrm{n}^{\circ} \text { empleados }\end{array}$} & $\begin{array}{c}\text { \% empleados en la } \\
\text { economía social }\end{array}$ & $\begin{array}{c}\text { Tasa de crecimiento } \\
2002 / 2003- \\
2009 / 2010^{*}\end{array}$ \\
\hline & Cooperativas & Associaciones & & \\
\hline España* $^{*}$ & 646.397 & 588.056 & $6,7 \%$ & $+42,5 \%$ \\
\hline Italia** $^{*}$ & 1.128 .629 & 1.099 .629 & $9,7 \%$ & $+66,7 \%$ \\
\hline
\end{tabular}

*Monzón y Chaves 2012; **Ventura y Zandonai 2014 
El impulso a la expansión de la empresa social, y en general al sector de la economía social, ha llevado, en la ultima década, a un creciente interés por parte del mundo de la investigación y por parte de la política, a nivel europeo y nacional. A nivel europeo está activa, desde los años noventa, la red de investigación EMES, que une universidades, instituciones de investigación e investigadores individuales "cuyo objetivo es el desarrollo de un organismo europeo de conocimientos teóricos y empíricos, pluralista en las disciplinas y metodologías, en torno a los conceptos de empresa y emprendimiento social". En Italia es activa la red de investigación Iris Network, cuyos socios, además de universidades y centros de investigación y formación, son entidades publicas, privadas y del Tercer Sector. En España la organización que más ha impulsado el conocimiento y el desarrollo de la empresa social es CIRIEC España (Centro Internacional de Investigación e Información sobre la Economía Pública, Social y Cooperativa): "una organización científica internacional no gubernamental, cuyos objetivos son promover la búsqueda de información, la investigación científica y la difusión de trabajos sobre los sectores y actividades que tienen por principal finalidad la de servir al interés general: la acción de los poderes públicos en materia económica; los servicios públicos, las empresas públicas y las entidades de Economía Social como las cooperativas, sociedades laborales, mutualidades, centros especiales de empleo y otras empresas sociales, fundaciones y asociaciones". También es importante el papel desempeñado por organizaciones y redes de organizaciones del Tercer Sector y de la economía social, comprometidos con la promoción de la cultura de la empresa social y con la construcción de un ambiente favorable a su desarrollo. En Italia, en particular, animan el debate y ejercen una función de estimulo el "Forum del Terzo settore" y los centros de servicios para el voluntariado, que, como en el caso de Cesvot en Toscana, han realizado investigaciones y acciones para promover la cultura y la práctica de la empresa social. También es importante el papel de organizaciones/consorcios de cooperativas sociales, que favorecen la creación de nuevas empresas, hasta creando "incubadoras de empresa social". En España el papel más importante es desempeñado por la Confederación Empresarial Española de Economía Social (CEPES), "una confederación empresarial, de ámbito estatal, cuyo carácter intersectorial la convierte en la máxima institución representativa de la Economía Social en España, constituyéndose como una plataforma de diálogo institucional con los poderes públicos".

\section{EL "ECO-SISTEMA" DE LA EMPRESA SOCIAL}

La empresa social ya no puede ser considerado un fenómeno nuevo, y aún menos una "moda", sino una realidad consolidada. Hasta hace una década la 
mayoría de los países europeos no tenían una ley sobre la empresa social. Hoy en día, también gracias a la acción de estimulo llevada a cabo por la Comisión Europea, sólo una minoría de los estados miembros de la UE no tienen un marco regulador. Entre estos podemos destacar tres modelos principales: el de la cooperativa, el de la sociedad y el de la forma abierta (Noya, 2009: 31). El primero identifica una forma de organización específica, la cooperativa. Ésta actúa como empresa social cuando no persigue como finalidad prevalente el interés de sus socios, sino el interés general. El primer ejemplo de esta estrategia es Italia, que fue el primer país en aprobar una ley sobre las cooperativas sociales en 1991, especificando rígidamente propósitos, actividades, incentivos y restricciones, además de las formas de gobierno que regulan la empresa social (Borzaga, 2009). El segundo modelo, de origen anglosajón, define la empresa social como una variante de la empresa privada, de la cual difiere por su finalidad social y por ser sin ánimo de lucro. Véase el modelo de la Community Interest Company, establecido en el Reino Unido en 2005. Un tercer modelo no vincula la empresa social con la condición de poseer un estatus legal específico, sino que la define según el cumplimiento de ciertos requisitos, de tal modo que pueden adquirir el estatus de empresa social organizaciones del Tercer Sector y empresas de capital. Este modelo ha sido introducido por primera vez en Bélgica en 1996 (Ley sobre las Societé a Finalité Social) y ha sido posteriormente adoptado en muchos otros países, a partir de Italia, donde la ley sobre la empresa social ha sido aprobada por el Parlamento en el 2006 (Ley 155/ 2006).

La primera normativa en materia de empresa social en Italia ha sido efectuada con la ley 381/1991, que estableció las cooperativas sociales. Con esta ley, Italia, en 1991, ha sido el primer país europeo que ha elaborado una respuesta a la necesidad de establecer un marco jurídico que regulase el componente del Tercer Sector más orientado al mercado. Ésta ya se había desarrollado en los años anteriores, en respuesta a la necesidad de ofrecer una respuesta a las nuevas necesidades sociales que no encontraban respuesta en los servicios públicos, y que encontraban dificultades para desarrollar sus actividades en el marco de la normativa sobre el voluntariado. En la búsqueda de una configuración organizativa adecuada para conciliar la necesidad de adoptar una estructura empresarial con el perseguimiento de su finalidad social, las nuevas organizaciones surgidas en los años ochenta se organizaron como cooperativas, definiéndose como cooperativas de solidaridad social. La ley 381/1991 establece un nuevo marco jurídico para las actividades de estas nuevas entidades, definiendo las cooperativas sociales como organizaciones de defensa de los intereses generales de la comunidad, con una orientación hacia la promoción humana y la 
integración social de los ciudadanos. La ley 381/1991, que sigue vigente, establece dos tipos de cooperativas sociales: la cooperativa social de tipo A, y la cooperativa social de tipo B. La primera es activa en la gestión de los servicios sociales y sanitarios, y en el campo de la educación. Las cooperativas sociales de Tipo B tienen como fin la creación de empleo para las personas desfavorecidas, y pueden operar en una pluralidad de sectores (agricultura, industria, comercio y servicios). La ley del 2006 sobre las empresas sociales se puso el objetivo de ampliar los confines de la empresa social, tanto en relación a las formas jurídicas adoptadas como en relación a los ámbitos de intervención. Con respecto a las formas legales, la ley 155/2006 atribuye la condición de empresas sociales según la posesión de algunos requisitos. Entre los principales: tener una estructura democrática; involucrar a los trabajadores y los beneficiarios en la gestión de la organización; no distribuir los beneficios. Las empresas sociales se puede configurar como asociaciones sociales, fundaciones, cooperativas y sociedades. La ley también establece los sectores de actividad en los que puede operar la empresa social: en el social, sanitario y socio-sanitario; en la educación y en la instrucción; en la tutela del medioambiente o de los bienes culturales: en la educación universitaria o extra-escolar; en el turismo social. Diez años después de su aprobación la ley 155/2006 no ha producido el efecto deseado por el legislador. A finales de 2013 sólo hay 774 empresas sociales ex lege, con un total de 29.000 empleados y 2.700 voluntarios. La principal explicación de esta falta de impacto se puede atribuir a la falta de incentivos y ayudas fiscales para las empresas sociales, que, en cambio, tienen que cumplir con una carga adicional, la redacción anual de un informe social (bilancio sociale), un informe sobre el impacto social de la empresa. A diferencia de las cooperativas sociales, que reciben ayudas fiscales, recibir el estatus de empresa social ex lege implica más cargas que ventajas. Además, las cooperativas sociales de Tipo A pueden trabajar en los sectores de intervención en los que se concentra la mayoría de las empresas sociales (socio-sanitario y educativo) y las cooperativas sociales de Tipo B pueden trabajar en todos los sectores. El resultado es que la forma de la cooperativa social sigue siendo la más utilizada para crear nuevas empresas sociales, hasta por los jóvenes. Las cooperativas sociales representan empresas sociales de facto y representan la forma predominante de las empresas sociales en Italia. A finales del 2013 había 12.570 cooperativas sociales en las que trabajaban cerca de 550.000 empleados y más de 70.000 voluntarios. El "ecosistema" de la empresa social en Italia, si extendemos la perspectiva, se completa con un ámbito de emprendimiento social "potencial", que comprende las organizaciones sin ánimo de lucro "orientadas hacia el mercado", por un lado, y las empresas que operan en los ámbitos de las empresas sociales estable- 
cidos por la ley 155/2006, por el otro. Las primeras son 82.231. Las segundas son 61.776 (Ventura y Zandonai, 2014).

En Italia, en síntesis, el "eco-ambiente" de la empresa social es muy amplio y fragmentado, y se compone de empresas sociales ex lege, empresas sociales de facto, empresas sociales potenciales (con particular referencia a las organizaciones del Tercer Sector que practican actividades comerciales de manera continua e integran voluntarios y trabajadores, pero también mirando a las empresas de capitales activos en los sectores de actividad de las empresas sociales).

España, al contrario de países como Italia, Francia, Reino Unido y Suecia, no está generalmente considerada entre los países europeos "en primera línea" del desarrollo de la empresa social. Sin embargo, "ha tenido un notable desarrollo del sector en los últimos treinta años, con una presencia creciente en múltiples actividades económicas" (Faura y Ventosa, 2011: 11). En España, aún más que en Italia, establecer con claridad la difusión del fenómeno es una tarea muy difícil, porque no hay una legislación específica sobre la empresa social, y consecuentemente no hay empresas sociales ex lege, y el mismo concepto de empresa social aparece todavía escasamente utilizado. Al contrario, el marco conceptual más relevante es el de economía social: un archipiélago dentro del cual podemos hallar la empresa social, como su componente más empresarial. Hasta la ley más reciente en la materia, como la Ley 5/2011, se refiere al concepto de economía social, y no hay referencia especifica al concepto de empresa social. Sin embargo, hay experiencias que, incluso sin referirse explícitamente y jurídicamente a ese término, se conforman a sus características y, como analizaremos a continuación, las definición de economía social por la ley 5/2011 se parece mucho a la definición de empresa social que da la Comisión Europea en la Iniciativa por el negocio social (2011), en sus elementos básicos. Finalmente, en España hay que tener en cuenta la extrema heterogeneidad a nivel regional, debido a las diferentes tradiciones y a las diferente legislación en la materia según las comunidades autónomas. Como se observa en el informe español realizado en el ámbito del estudio sobre el ecosistema de la empresa social en Europa promovido por la Comisión Europea, "en España, mientras que el concepto de economía está regulado, éste no es el caso de las empresas sociales, que a pesar de que existen en la realidad, sobre todo desde el inicio de la crisis económica, aún no han sido reguladas legalmente. Por otra parte, la naturaleza descentralizada del Estado español construye un mosaico diverso a nivel regional" (European Commission, 2015b: 3). Andalucía, País Vasco, Valencia y Murcia son las regiones en las que el fenómeno de la empresa social aparece más consolidado. 
Recorriendo las etapas del desarrollo de la economía social, podemos hallar su primer reconocimiento legal en la Ley de Presupuestos Generales del Estado, en 1990 (Priede Bergamini et al., 2014) y con la creación, en el año 1991 del Instituto Nacional de Fomento de la Economía Social, (INFES) - Ley 31/1990, en la que se utiliza por primera vez el concepto de Economía social. En el año 1997, el Instituto deja sus funciones a la Dirección General del Fomento de la Economía Social y del Fondo Social Europeo. Finalmente, la Ley 27/1999, de 16 de julio, de Cooperativas, incorpora el Consejo para el Fomento de la Economía Social como órgano asesor y consultivo para las actividades relacionadas con la economía social. Hoy en día, como en Italia, en el ámbito de la economía social market-oriented los actores principales, que representan empresas sociales de facto, son las cooperativas sin ánimo de lucro, o sea, las cooperativas de iniciativa social y las cooperativas de integración social. Las cooperativas de iniciativa social, según la Ley de Cooperativas españolas de 1999, "tienen como finalidad la prestación de servicios asistenciales mediante la realización de actividades sanitarias, educativas, culturales u otras de naturaleza social, o bien el desarrollo de cualquiera actividad económica que tenga por finalidad la integración laboral de personas que sufran cualquier clase de exclusión social, y, en general, la satisfacción de necesidades sociales no atendidas por el mercado". La presencia de este tipo de cooperativa es marginal: 566, en el 2009, respecto a más de 20.000 cooperativas. En cambio, las empresas cooperativas de integración social, han sido promovidas por las legislaciones de las comunidades autónomas en materia de cooperación, y, de manera similar a las cooperativas sociales de Tipo B en Italia, tienen como objetivo principal la integración laboral y social de personas discapacitadas y con riesgo de marginación social $^{2}$.

En 2011 se aprueba, con amplia mayoría, la Ley 5/2011 sobre la economía social, con el objetivo de establecer un "marco jurídico de apoyo y reconocimiento de la economía social como actividad económica diferenciada que requiere de acciones sustantivas de apoyo y fomento público", como recita el preámbulo, en que se hace referencia a la «Charte de l'économie sociale» francesa y al «Conseil Wallon de l'Économie sociale» de Bélgica, además del impul-

${ }^{2}$ A nivel nacional las empresas de inserción son disciplinadas por la Ley 44/2007. A nivel autonomico las leyes de referencia son: en Aragón, los decretes 33/2002 y 37/2006; en Baleares, el Decrete 60/2003; en Canarias, los decretes 32/2003 y 137/2009; en Castilla la Manca, la Ley 5/1995; el Castilla León, el decrete 34/2007; en Cataluña, la Ley 27/2002; en La Rioja, la Ley 7/2003; en Madrid, el decrete 32/2003; en Navarra, el decrete foral 130/1999; en País Vascos, los decretes 305/2000 y 182/2008, en la Comunidad Valenciana, la Ley $1 / 2007$. 
so dado por el Comité Económico y Social Europeo en 1992, con la presentación de tres Propuestas de Reglamento de Estatutos de la Asociación Europea, de la Cooperativa Europea y de la Mutualidad Europea y del siguiente Estatuto de la Sociedad Cooperativa Europea; aprobado por el consejo en el 2003. En línea con sus marcos de referencia, le ley española define la economía social como un conjunto de actividades empresariales que tienen como fin el interés colectivo, que respetan el principio de la primacía de la dimensión social sobre la dimensión del capital, que realizan procedimientos de gestión trasparente y democrática, donde el poder decisional deriva de la contribución individual y no de la cuota de capital. Además, se afirma que el lucro deberá ser repartido según el trabajo prestado por sus miembros y según la finalidad social de la organización. Finalmente, se hace referencia a la promoción de la solidaridad, a la paridad de género, a la contribución a la cohesión social, a la sostenibilidad y a la inclusión de sujetos con riesgo de exclusión social, a la independencia de las autoridades públicas. La definición contiene muchas características de la definición de empresa social de EMES, con referencia a la dimensión social, pero pone menor énfasis sobre la dimensión empresarial.

Como sintetiza Triper (2013), la economía social se caracteriza como un "paraguas" que integra siete premisas: 1) riqueza asociativa y empresarial, como premisa de generación de innovación social; 2) Cohesión social y geográfica: las entidades de la economía social tienen raíces en los lugares e impulsan procesos de desarrollo económico y social, a partir de una valorización de sus recursos materiales e inmateriales. Desde esta perspectiva hay que señalar los proyectos de recuperación urbana y de empresas por parte de los trabajadores; 3) Sostenibilidad en el mantenimiento del empleo; 4) Primacía de las personas sobre el capital; 5) Integración, en sentido amplio; 6) Compromiso con las personas a las que se dirigen los servicios y promoción de la participación; 7) Creación de empleo deslocalizado y sostenible. Podemos resumir afirmando que la empresa social es un movimiento global que promueve un modelo de desarrollo social y económico, fundado sobre una "vuelta" a los territorios, y que invierte la desterritorialización de la economía global.

No todas las organizaciones incluidas en el universo de la economía social pueden ser directamente asimiladas a empresas sociales, ya que ésta incluye cualquier tipo de organización que desarrolla actividades económicas y empresariales, y que responde a los principios contenidos de la ley. El resultado es que el ámbito de la economía social, según la normativa española, puede ampliarse hasta comprender empresas privadas, que no tienen una explícita y prevalente finalidad social, así como organizaciones de voluntariado en las que la dimensión económica y empresarial es muy marginal, con respecto a las actividades pre- 
valentes. En el momento de intentar sintetizar la naturaleza y las dimensiones de la empresa social en España, es necesario individuar un subconjunto de organizaciones de la economía social, cuyas características reflejan la definición EMES de empresa social, excluyendo, de un lado, empresas "no suficientemente sociales" como las sociedades laborales; y organizaciones "no suficientemente empresariales", como las asociaciones de voluntariado en las que la dimensión empresarial no es prevalente. Las sociedades laborales son 13.465, y representan las organizaciones más difundidas dentro de la economía social, que todavía no cumplen con las características que definen la empresa social según una definición estrecha. Son empresas con responsabilidad limitada, donde la mayoría del capital pertenece a los trabajadores, y que están gestionadas de manera democrática y en las que ningún miembro puede sumar más del $33 \%$ de la propiedad. Las asociaciones implicadas en actividades empresariales, y que por esto forman parte de la economía social, pero que no pueden ser directamente definidas como empresas sociales son 7.086 , a las que hay que añadir 54 fundaciones.

Al contrario, según el enfoque a la empresa social seguido por la Comisión Europea (Comisión Europea 2013: 2015a, 2015b), de los actores incluidos en la economía social, los que pueden ser incluidos en el ámbito de la empresa social de facto son las asociaciones y las empresas activas en el mercado, las 556 cooperativas de iniciativa social y las 200 empresas de integración social, los 490 centros especial de empleo, cuyo fin es la inserción de minusválidos, a las que se suman 402 sociedades mutuas y 219 cofradías de pescadores.

De esta manera, podemos estimar en 7.830 organizaciones el universo de la empresa social de facto en España. Se trata de un universo menos amplio del italiano, donde, frente a las 774 empresas sociales ex lege, solo las cooperativas sociales son 12.570. Sin embargo, la fragmentación del contexto español no favorece la realización de estimaciones claras, así que frente de estos datos, que se refieren a una definición más restringida, si incluimos a todos los tipos de cooperativa y a las sociedades laborales, el ámbito de la empresa social potencial sube, en cuanto que solo estas dos incluyen 335.000 trabajadores $y$, según datos CEPES (Tripper, 2013), la economía social, o sea un ámbito mas amplio de la empresa social, pero en que se encuentran muchas experiencias de empresa social potencial, con 44.563 empresas, emplea el 12,5\% del total de los empleados en el país y alcanza el 10\% del PIB.

Lo más importante es que en España, como en Italia, hay ejemplos de actividades empresariales, a menudo protagonizadas por jóvenes, que escapan de las definiciones y de los confines tradicionales, que representan enfoques y aptitudes nuevos en la empresa y que ligan de manera inseparable la dimensión 
empresarial a la dimension social, y que sin embargo. tienen la forma jurídica de empresa de capitales. Para integrar este tipo de experiencias en el mundo de la empresa social y valorizar su papel de innovación, en términos de capacidad de integrar construcción de valor económico y social, y de contribuir a un desarrollo socialmente y económicamente sostenible, hay que ampliar ulteriormente los confines de la empresa social, más allá del tradicional ámbito de la economía social, que, en la tradición europea, identifica la dimensión social de la empresa directamente con el tipo de actividad que ejerce, más que con su finalidad y su enfoque; al punto que sigue identificando la empresa social con una organización activa en la producción de servicios a la persona y que tiene sus raíces en el Tercer Sector. Eso supone, de alguna manera, integrar el enfoque tradicional, de tipo europeo, a la empresa social, que la identifica como una empresa colectiva, de naturaleza asociativa, básicamente activa en la provisión de servicios a la persona, con un enfoque más abierto, de origen anglosajón, según el cual es empresa social todo tipo de empresa con finalidades sociales y comprometida con la realización de innovación social.

El desarrollo de un enfoque más amplio a la empresa social está hoy en día caracterizando los proyectos de reforma debatidos en algunos países europeos, incluso Italia. Ese tipo de ampliación de la empresa social tiene el objetivo de promover un conjunto de prácticas de innovación social, con particular referencia al protagonismo juvenil, favorecer un proceso de "civilización" de la economía y promover la construcción de un nuevo modelo económico y social, que podría ser inhibido por una definición de la empresa social restringida a sus ámbitos tradicionales. Por otro lado, al ampliar los confines de la empresa social, hasta incluir una pluralidad de prácticas empresariales, de enfoques y de marcos jurídicos, existe el riesgo de "desnaturalizar" su misma identidad. En este sentido, el desafío, en el actual contexto de crisis económica y social, es promover la difusión y la evolución de la empresa social, explorando nuevas direcciones y abriendo nuevas oportunidades, con el fin de maximizar su impacto, en términos de innovación social y de creación de valor económico y social; sin debilitar, sino más bien, manteniendo y fortaleciendo el equilibrio entre la dimensión empresarial y la dimensión social. Para llevar a cabo esto, hay que volver a definir, con claridad, la frontera entre las organizaciones de empresa social y las organizaciones del Tercer Sector que, aunque activos en la producción de servicios y con trabajadores asalariados, siguen siendo básicamente non market-oriented. En segundo lugar, frente a una tendencia común, en Europa, de incluir en el concepto de empresa social empresas de capitales y activos en una pluralidad de ámbitos, diferente de los servicios a la persona, o sea organizaciones extrañas a la tradición europea de la economía 
social; hay que sentar de manera clara la frontera entre empresa social y empresa privada "ética", o "socialmente responsable". En Italia, el tema de la delimitación del ámbito de la empresa social dentro del contexto más amplio del Tercer Sector y, paralelamente, de ampliación de las prácticas que pueden ser consideradas como empresa social, está en el centro del debate sobre la Reforma del Tercer Sector. También en España hay un debate sobre nuevos proyectos de reforma, que introduzcan de manera especifica el concepto de empresa social, como ámbito más especifico y solo en parte coincidente con el mundo de la economía social.

De las orientaciones que prevalecerán, dependerá el futuro de la empresa social. Esta, desde una perspectiva critica, cada vez más representarán una herramienta para externalizar los servicios públicos y para generar servicios baratos. Según una perspectiva optimista, al contrario, la empresa social se con-

Tabla 2. La normativa sobre economía social y empresa social en España y en Italia

\begin{tabular}{|c|c|c|}
\hline $\begin{array}{c}\text { España-Ley 5/2011, } \\
\text { de } 29 \text { de marzo, de } \\
\text { Economía Social }\end{array}$ & $\begin{array}{l}\text { Italia-Legge } 381 / 1991 \\
\text { sulle cooperative sociali }\end{array}$ & $\begin{array}{c}\text { Italia-Decreto } \\
\text { Legislativo } 24 \text { marzo } \\
\text { 2006, n. } 155 \text { "Disciplina } \\
\text { dell'impresa sociale, a } \\
\text { norma della legge } 13 \\
\text { giugno } 2005, \text { n. } 118 \text { " }\end{array}$ \\
\hline $\begin{array}{l}\text { "El objetivo básico de la Ley } \\
\text { es configurar un marco jurí- } \\
\text { dico que, sin pretender sus- } \\
\text { tituir la normativa vigente } \\
\text { de cada una de las entidades } \\
\text { que conforma el sector, su- } \\
\text { ponga el reconocimiento y } \\
\text { mejor visibilidad de la eco- } \\
\text { nomía social, otorgándole } \\
\text { una mayor seguridad jurídi- } \\
\text { ca por medio de las actua- } \\
\text { ciones de definición de la } \\
\text { economía social, establecien- } \\
\text { do los principios que deben } \\
\text { contemplar las distintas en- } \\
\text { tidades que la forman" (art. } \\
\text { 3). }\end{array}$ & $\begin{array}{l}\text { "Le cooperative sociali } \\
\text { hanno lo scopo di perse- } \\
\text { guire l'interesse generale } \\
\text { della comunita' alla pro- } \\
\text { mozione umana e all'inte- } \\
\text { grazione sociale dei citta- } \\
\text { dini attraverso: } \\
\text { a) la gestione di servizi } \\
\text { socio-sanitari ed educativi; } \\
\text { b) lo svolgimento di atti- } \\
\text { vita' diverse -agricole, in- } \\
\text { dustriali, commerciali o di } \\
\text { servizi- finalizzate all'inse- } \\
\text { rimento lavorativo di perso- } \\
\text { ne svantaggiate". (art. 1). }\end{array}$ & $\begin{array}{l}\text { "Possono acquisire la qua- } \\
\text { lifica di impresa sociale } \\
\text { tutte le organizzazioni pri- } \\
\text { vate, ivi compresi gli enti } \\
\text { di cui al libro V del codice } \\
\text { civile, che esercitano in via } \\
\text { stabile e principale un'atti- } \\
\text { vità economica organizza- } \\
\text { ta al fine della produzione } \\
\text { o dello scambio di beni o } \\
\text { servizi di utilità sociale, di- } \\
\text { retta a realizzare finalità di } \\
\text { interesse generale..." (art. } \\
\text { 1). }\end{array}$ \\
\hline
\end{tabular}


vertirá, en los próximos años, en un extraordinario laboratorio de innovación social, donde, gracias a la orientación social y al enraizamiento en el territorio, se generarán respuestas a las necesidades sociales no satisfechas por lo público y por lo privado, y se promoverán procesos virtuosos de crecimiento social y económico.

El estímulo a los proyectos de reforma, y, más generalmente de los proyectos de promoción de la empresa social, se ve en los datos de la última década, en la que la empresa social (en el sentido más amplio), en un período de crisis, ha sido caracterizada por dinámicas anticíclicas y ha seguido produciendo nuevos puestos de trabajo, empleando, de manera particular, jóvenes. Los datos españoles nos dicen que el $47 \%$ de los empleados en la economía social son menores de 40 años (Triper, 2013); un dato importante, en un contexto de desempleo juvenil que supera el $50 \%$.

\section{EL FUTURO DE LAS EMPRESAS SOCIALES: ¿HERRAMIENTA DE EXTERNALIZACIÓN DE SERVICIOS PÚBLICOS Y DE REDUCCIÓN DE LOS GASTOS O PROMOTORES DE INNOVACIÓN SOCIAL?}

La creciente incapacidad por parte del actor público, de responder a las necesidades plurales de sociedad complejas, en un contexto de reducción de recursos, dio origen a tres respuestas alternativas. La primera, de defensa del modelo social tradicional, postula la necesidad de mantener/extender los ámbitos de acción de lo público, como única posibilidad de garantizar un modelo universalista de protección de los derechos. La segunda, de tipo neoliberal, atribuye un papel central a los actores privados, afirmando que solo el mercado puede garantizar sostenibilidad económica y eficacia. Entre el modelo estatalista y el modelo neoliberal se va difundiendo el interés hacia un tercer modelo, el que ve en la economía social no simplemente un ámbito residual, sino el ámbito estratégico de desarrollo económico, social y civil (Jiménez Escobar, Morales Gutiérrez, 2011: 36). Esta valoración del Tercer Sector, sin embargo, tiene sus raíces en la tradición europea del voluntariado y de la cooperación, y ve a España y Italia como protagonistas, sea a nivel teórico como en términos de prácticas: en los dos países la empresa social está viviendo una importante fase de expansión, en términos de ámbitos de actividad, de destinatarios de los servicios y de trabajadores involucrados. A la empresa social se la mira como herramienta de desarrollo sostenible, de movilización de los recursos tangibles e intangibles en los territorios, y, sobre todo, como instrumento de innovación social, hasta el punto de que en los dos países el tema de la empresa social es de manera creciente objeto de interés por parte de las instituciones. 
Sin embargo, el carácter innovador de la empresa social no surge simplemente de una empresarialización del Tercer Sector tradicional, y mucho menos como consecuencia de la transferencia de servicios fundamentales del Estado a asociaciones, cooperativas y empresas sociales, si con eso se persigue el simple objetivo de reducción de los gastos públicos. Al contrario, la innovación surge de la capacidad por parte de estas organizaciones de generar respuestas innovadoras a demandas emergentes, de su capacidad de crear al mismo tiempo valor social y económico, de satisfacer necesidades individuales (de sus beneficiarios directos y de sus socios y trabajadores) y colectivas, de activar dinámicas de cambio de medio y largo plazo, de estimular dinámicas de emprendimiento, de empoderamiento y de valorización en el territorio. Eso, de acuerdo con la definición propuesta por Mullan et al. (2007) en el Libro Blanco sobre la Innovación Social: lo que diferencia el concepto de innovación social del concepto de innovación empresarial es el objetivo primario de satisfacer necesidades sociales y no la maximización de los beneficios de la empresa.

En la base de los caminos de la innovación realizados por las empresas sociales está la capacidad de conectar los recursos y conocimientos disponibles en la zona y de involucrar activamente a los destinatarios de los servicios. Esto les permite anticiparse a las necesidades emergentes experimentando respuestas nuevas. Practicar innovación, por parte de las empresas sociales, no significa solamente crear nuevos productos o servicios, sino integrar eficiencia y equidad. Solo de esta manera el desarrollo de empresas sociales puede contribuir a experimentar nuevas modalidades de encuentro entre acción social y acción económica, y por esa vía construir un nuevo modelo de economía y de sociedad, en el que la economía social adquiere un papel central.

La función de innovación social llevada a cabo por el empresa social surge de su capacidad de captar con antelación -en comparación con las instituciones públicas- las nuevas necesidades y de proporcionar respuestas y modalidades de intervención más flexibles, y por lo tanto más eficaces, gracias a la inclusión de los beneficiarios y a la capacidad de conectar y valorizar recursos, habilidades y actitudes diferentes. La empresa social desarrolla respuestas multidimensionales, cuya eficacia se ve favorecida por el elemento de la participación activa de los destinatarios. En comparación con otras organizaciones, tanto públicas como privadas, el Tercer Sector y la empresa social están más cerca de los ciudadanos y más arraigadas en los contextos locales, y por lo tanto son capaces de generar procesos de innovación que no siguen un proceso "topdown", sino una dinámica de transformación "bottom-up". La innovación social, como respuesta innovadora a las necesidades sociales, es un esfuerzo de carácter colectivo, y no el producto de un empresario iluminado y dotado con 
habilidades extraordinarias. Es un proceso de creación de valor que se basa en la combinación, la creación de redes, la hibridación, la reconexión de los recursos existentes; en un proceso en el que la suma de los recursos, tangibles e intangibles existentes, genera un valor más alto que el de la suma de las partes. Es, en este sentido, un proceso de inteligencia colectiva (Rheingold, 2002).

Las empresas sociales no sólo conciben su papel como el de los productores de bienes y servicios que persiguen un encuentro entre la oferta y la demanda, sino que incluyen a los destinatarios en la preparación y ejecución de la respuesta. Este enfoque se concreta si las diferentes almas del Tercer Sector interactúan en redes, generando un valor añadido que brota de esta misma capacidad de diálogo y cooperación. Desde este punto de vista, el modus operandi de la empresa social es opuesta a la de la empresa privada, que, persiguiendo un fin lucrativo, mantiene en secreto las innovaciones producidas, para mantener una ventaja competitiva. Esa aptitud, se señala, se encuentra a menudo también en el Tercer Sector, pero cuando esto sucede se traiciona el espíritu del voluntariado y del emprendimiento social, que tiene como objetivo final la creación de un beneficio para la comunidad, y no sólo para la empresa. Un corolario de este enfoque diferente es que un proceso de innovación social producido por una organización o una red de organizaciones, para lograr la máxima eficacia, debe salir de los confines en el que se produce, extenderse y consolidarse en otros contextos y otros actores. La empresa social, por definición, no "tiene celos" de su aportación innovadora, sino que la comparte en una óptica de red, convirtiendo la innovación de un recurso interno a la organización, a un recurso para el contexto territorial en el que opera la empresa, y finalmente en un recurso compartido por la sociedad más amplia. En síntesis, eso significa no solo que la empresa social no produce beneficios privados produciendo externalidades negativas para la comunidad, sino que tiene el explícito objetivo de producir externalidades positivas, o sea, producir valor social (Fernández Fernández, 2012). Detrás de esta manera de relacionarse con el exterior, surge una nueva manera de vivir, pensar y practicar la empresa y la creación de valor. La empresa social exprime un nuevo enfoque a la economía, definida por el concepto de "shared valued theory" (Porter y Kramer, 2011). La shared valued theory es un modelo en el que la creación de valor individual no es en contraposición con la creación de valor compartido; sino que representa una manera de crear valor para la sociedad. Como escriben Porter e Kramer, "el valor compartido no es corporate social responsibility, no es filantropía, y tampoco sostenibilidad, sino una manera para alcanzar el éxito económico". En otros términos, la perspectiva de la shared values theory está en la raíz de los proyectos de innovación social promovidos por las empresa 
sociales porque integran la creación de oportunidades de trabajo con las oportunidades de promoción social. Como afirma Zamagni, el desarrollo de la empresa social, así concebido, no sirve solo para crear un ámbito de economía ética, sino también para estimular un proceso más ambicioso de "civilización de la economía" (Zamagni, 2013). Ésta, en los países más afectados por la crisis económica y social generada por el modelo neoliberal, España y Italia, junto con Grecia y Portugal, puede encontrar su laboratorio privilegiado. La empresa social puede ser una herramienta vital para el desarrollo económico y el desarrollo social. En particular, puede ser una oportunidad para los jóvenes, ofreciendo respuestas a la crisis económica e indicando la vía de un nuevo modelo de desarrollo.

\section{CONCLUSIONES: LAS PERSPECTIVAS DE DESARROLLO DE LA EMPRESA SOCIAL ENTRE LUCES Y SOMBRAS.}

El concepto de empresa social intenta integrar enfoques, finalidades y modalidades que, tradicionalmente, han pertenecido a mundos diferentes: el de la economía, reino de la acción instrumental, y el del voluntariado, reino de la acción solidaria. Para que esta hibridación favorezca un modelo de desarrollo centrado el la civilización de la economía (Zamagni, 2013) y no al revés, en una instrumentalización del Tercer Sector, y favorezca una dinámica virtuosa de creación de trabajo en organizaciones innovadoras y comprometidas con el interés público; en el ámbito de la tradición europea se ha producido una definición de empresa social que identifica con precisión sus fronteras con las empresas con fines de lucro, y -supuestamente- con las organizaciones sin ánimo de lucro, activas en la provisión de servicios que, no obstante, no actúan de manera prevalente como empresa.

Tanto en Italia como en España, la empresa social, en tiempo de crisis, ha sido capaz de confirmar su potencialidad, en términos de integración en la creación de valor individual y social. Actuando de manera anti-cíclica, ha aumentado sus actividades y, como consecuencia, ha sido el único ámbito económico que ha producido nuevo empleo, sobre todo para los jóvenes. Precisamente, por su dinamismo existe un debate abierto sobre cómo promover ulteriormente el desarrollo de la empresa social, también explorando nuevos ámbitos de actividad. Esto a partir de la premisa de que la empresa social, en línea con la tradición europea, sigue siendo prevalentemente activa en la provisión de servicios personales, en el sector socio-sanitario, en el ámbito educativo y en la integración socio-laboral de los desfavorecidos. Esto pasa en España, donde la empresa social representa, a falta de una normativa específica, un subconjunto de la economía social; y en Italia, donde la Ley 155/2005 supo, solo en parte, 
ampliar los confines de la empresa social, que sigue coincidiendo, en su expresión principal, a las cooperativa sociales.

En las últimas décadas, el Tercer Sector ha experimentado procesos de transformación, cuantitativa y cualitativa, dirigidos hacia su profesionalización y hacia una ampliación de sus funciones. Estas transformaciones reflejan un cambio de enfoque para el Tercer Sector, que afecta particularmente a los jóvenes. Éstos, en un contexto de crisis económica y de desempleo juvenil que tanto en Italia, como en España, es particularmente alto, ven el Tercer Sector y a la empresa social como una herramienta de conciliación virtuosa entre compromiso social, formación y profesionalización. Una cuestión que queda abierta es la identificación de la demarcación y de las posibles relaciones entre las dos almas del Tercer Sector, el voluntariado y la empresa social. Se trata de dos mundos contiguos y unidos por objetivos y directrices comunes, que deben seguir siendo conceptualmente distintos.

En Italia una ley-delega de reforma del Tercer Sector, aprobada en Abril de 2015, intenta llevar a cabo una reorganización y simplificación de este amplio mundo, que favorezca una diferenciación más clara entre voluntariado y empresa social y que, al mismo tiempo, amplíe los límites de esta última. El objetivo es reunir bajo un mismo techo todas las diversas formas de empresas sociales que existen hoy en día en Italia, hasta incluir organizaciones que adopten un enfoque más explícitamente empresarial y que produzcan bienes o servicios diferentes a los que tradicionalmente caracterizan la empresa social. Con esta reforma, el gobierno italiano quiere promover el desarrollo de la empresa social como respuesta innovadora a la crisis, integrando el tradicional enfoque europeo, que define la empresa social como la dimensión más empresarial de la economía social, con el enfoque típico de la tradición anglosajona. Según el primero, para definirse empresa social ha de ser exclusivamente sin ánimo de lucro, participar en actividades de claro interés social, ser una empresa de tipo colectivo y ser gestionada democráticamente. En cambio, en la tradición anglosajona la empresa social, básicamente, se define por ser sin ánimo de lucro y por perseguir de manera genérica a objetivos sociales, a pesar de sus características de gestión y de su actividades. La reforma del Tercer Sector, en su forma actual, amplía los posibles ámbitos de actividad de la empresa social, hasta incluir todos los ámbitos económicos, e incluso prevé la posibilidad de una limitada redistribución del lucro (Zandonai y Venturi, 2014), haciendo una genérica referencia a una "medición del impacto social", de tipo ex-post; de tal manera que la definición misma de empresa social como empresa "privada sin fines de lucro", se vuelve, de forma más general, en una empresa "que tiene como objetivo primordial el logro de impactos sociales positivos medibles". De esta 
manera, no solo se adoptan elementos típicos de la concepción anglosajona a la empresa social, sino que también se propone una definición aun más amplia, ya que desaparece la prohibición de distribución de beneficios. La nueva Ley sobre el Tercer Sector, en la intención del gobierno, representará un paso atrás en la realización del principio de subsidiariedad vertical y horizontal (Donati y Collozzi, 2004), aumentando la posibilidad de elección por los ciudadanos y sentará las bases sobre las que construir un "nuevo modelo de Estado de Bienestar de tipo participativo", basada en una gobernanza social ampliada en el diseño y en la gestión de los servicios sociales de acuerdo a los principios de equidad, eficiencia y solidaridad social. En otros términos, la ley promueve una plena transición desde el modelo tradicional del "Estado de bienestar" a un modelo de "Sociedad del bienestar", en el que adquiere centralidad el componente más profesionalizado y market-oriented del Tercer Sector, o sea, la empresa social, a la que se le atribuye la capacidad, además de ofrecer respuestas a necesidades no satisfechas ni por el público ni por el privado, de promover crecimiento económico y creación de empleo. Para los promotores, la Reforma del Tercer Sector, eliminando en última instancia las barreras entre ámbitos de acción, llevará a cabo la civilización de la economía, demostrando que "realmente podemos servir al mercado como un medio para fortalecer el vínculo social. De hecho, el proprium de la empresa social es llevar la actividad económica del mercado a su vocación original de ser un medio para humanizar las relaciones entre las personas, una vocación que se olvidó después de la revolución industrial" (Zamagni, 2005).

Las críticas que han sido expresadas a la ley-delega de reforma del Tercer Sector manifiestan el miedo a que este tipo de contaminación, debido a una expansión excesiva de los límites de la empresa social, altere el equilibrio entre la dimensión empresarial y la dimensión social a favor de la primera, con el efecto de alejar la normativa italiana de la tradición europea de la empresa social, con particular referencia a la previsión de una distribución limitada de los beneficios (Borzaga y Sacconi, 2014). Precisamente, este tipo de miedo relativo explica porqué en el Parlamento italiano la ley fue aprobada por mayoría simple y se encontró con el voto contrario de los partidos de oposición, que expresaron el miedo a que la reforma, de hecho, no favorezca procesos de innovación social, sino el desarrollo de empresas con ánimo de lucro disfrazadas de empresas sociales, en las que la dimensión social es muy reducida. Con la consecuencia de favorecer un ulterior desplazamiento de los servicios básicos a organizaciones, como las cooperativas, que pueden pagar menos a los trabajadores, y ofrecer servicios de menor calidad. Al fin y al cabo, este enfoque critico, en parte, contribuye a explicar porqué, en un contexto de crisis y de recortes, el sector de la empresa social es el único en expansión. 


\section{BIBLIOGRAFÍA}

Ascoli, U. y Ranci, C. (2003). Il welfare mix in Europa, Carocci, Roma.

Borzaga, C. y Zandonai, F. (coords.) (2009). Limpresa sociale in Italia. Economia e istituzioni dei beni comuni. Rapporto Iris Network, Roma: Donzelli.

Borzaga, C. (2009). "Limpresa sociale". En Bruni, L. y Zamagni, S. (coords.), Dizionario di economia civile. Troina: Città nuova.

Borzaga, C. y Defourny, J. (coords.) (2001). Limpresa sociale in prospettiva europea. Diffusione, evoluzione, caratteristiche ed interpretazioni teoriche. Trento: Edizioni 31.

Borzaga, L. y Fazzi, L. (2011). Le imprese sociali, Roma: Carocci.

Borzaga C. y Sacconi L. (2014). "La riforma al varco: opportunità e rischi". Impresa sociale, 4.

Chaves, R. y Monzon, J. (2005). "La Economia Social en la Union Europea". CESE/ COMM/05/2005, http://www.socialeconomy.eu.org/spip.php?article421.

Comisión Europea, Mercado Interior y Servicios (2004). La iniciativa de emprendimiento social de la Comisión Europea. http://ec.europa.eu/internal_market/publications/docs/sbi-brochure/sbi-brochure-web_es.pdf

Defourny, J. (2001). "From Third Sector to Social Enterprise". En Borzaga, C. y Defourny, J. (coords.). The Emergence of Social Enterprise, London and New York: Routledge: 1-28.

Defourny, J. y Nyssens, M. (2010). "Conceptions of Social Enterprise and Social Entrepreneurship in Europe and the United States: Convergences and Divergences",. Journal of Social Entrepreneurship, 1: 32-53.

Defourny, J. y Nyssens, M. (2012). "The EMES Approach of Social Enterprise in a Comparative Perspective”. EMES Working Papers Series, 12/03.

Donati, P. y Colozzi, I. (2005). La sussidiarietà. Che cos'è e come funziona. Carocci, Roma.

Emes (2013). "Social Enterprise“. http://www.emes.net/about-us/focus-areas/socialenterprise.

Esping-Andersen, G. (1990). The three worlds of welfare capitalism. Princeton University Press, Princeton.

European Commission (2011). Social Business Initiative, Communication from the Commission to the European Parliament. The Council, the European Economic and Social Committee and the Committee of the Regions, Brussels.

European Commission (2015a). "A map of social enterprises and their eco-systems in Europe".

European Commission (2015b). "A map of social enterprises and their eco-systems in Europe - Country Report, Spain”.

European Commission (2015c). "A map of social enterprises and their eco-systems in Europe - Country Report, Italy".

Faurai y Ventosa (2011). "Antecedentes". En AA.VV., Ley 5/2011 de Economía social, Cepes.

Fazzi, L. (2014). Imprenditori sociali innovatori. Casi di studio nel terzo settore. Milano: Franco Angeli. 
Fernández Fernández, M.T., Montes Pineda O., Asián Chaves R. (2012). La Innovación social como solución a la crisis: hacia un nuevo paradigma de desarrollo. Ponencia presentada a las XIII Jornadas de Economía Crítica, Los costes de la crisis y alternativas en construcción, Sevilla.

Ferrera, M. (1993). Modelli di solidarietà. Politica e riforme sociali nelle democrazie. Bologna: il Mulino.

Forno F. (2014). "Tra resilienza e resistenza. L'emergere delle pratiche economiche alternative". En Alteri, L. y Raffini, L. (coords.), La nuova politica. Mobilitazioni, movimenti e conflitti in Italia, EdiSes, Napoli, 71-90.

Gem (2009). Report on Social Entrepreneurship. http://www.gemconsor- tium.org/download/1326185555889/GEM\%20Spain\%202009\%20Report.pdf.

Jímenez Escobar, J. y Morales Gutierrez, C.M. (2011). "Social Economy and the Fourth Sector, Base and Protagonist of Social Innovation". Ciriec-España: Revista de Economía Pública, social y cooperativa, 77: 33-60.

Maino, F. y Ferrera, M. (a cura di) (2013). 2wel. Primo rapporto sul secondo welfare in Italia. Centro di Ricerca e Documentazione Luigi Einaudi.

Monzón Campos, J.L. y Chaves Ávila, R. (2012). The Social Economy in the European Union. European Economic and Social Committee.

Murray, R.; Caulier-Grice, J.Y Mulgan, G. (2010). The open book of social innovation. Nesta: The Young Foundation.

Noya, M. (coord.) (2009). The Changing Boundaries of Social Enterprise, OECD.

Nyssens, M. (coord.) (2006). Social Enterprise - At the Crossroads of Market, Public Policies and Civil Society. London and New York: Routledge.

OECD/European Commission (2013). Policy Brief on Social Entrepreneurship. Entrepreneurial Activities in Europe.

Porter, M.E. e Kramer, M.R. (2011). Creating Social Value. Harvard Business Review.

Priede Bergamini, T., López-Cózar, Navarro y Rodríguez López, Á. (2014). "The specific economic and legal framework for social entrepreneurs. A comparative study of different countries". Ciriec-España: Revista de Economía Pública, social y cooperativa, 80: 5-28.

Rheingold, H. (2003). Smart mobs. Tecnologie senza fili, la rivoluzione sociale prossima ventura. Raffaello Cortina, Milano.

Triper, B. (2013). El empresa social como parte de la economía social. Cepes.

Venturi, P. y Zandonai, F. (coords.) (2012). Limpresa sociale in Italia. Pluralità dei modelli e contributo alla ripresa, Rapporto Iris Network. Milano: Edizioni Altraeconomia.

Venturi, P. y Zandonai, F. (coords.) (2014). Limpresa sociale in Italia. Identità e sviluppo in un quadro di riforma. Rapporto Iris Network, Milano: Edizioni Altraeconomia.

Villajos, E.; Sanchis, J.R. y Ribeiro, D. (2012). "Empresas sociales: aproximacion empirica a su direccion estrategica. El caso valenciano". CIRIEC-Espana, Revista de Economia Publica, Social y Cooperativa, 75: 199-221.

Zamagni, S. (2005). "La legge sull'impresa sociale: un'occasione storica da non sprecare". Impresa sociale, 2.

Zamagni, S. (2013). Impresa responsabile e mercato civile. Il Mulino, Bologna. 
ANDREA PIRNI is Associate Professor in Political Sociology at the University of Genova (Department of Political Sciences). He teaches Political sociology, Sociology of public opinion and Sociology of administration. He is member of the executive committee of the Inter-University Centre for Political Sociology (Ciuspo - Firenze) and board member of the research committee Sociologia politica (Associazione Italiana di Sociologia). He is member of the editorial board of the scientific journals «SocietàMutamentoPolitica. Rivista italiana di sociologia», «Partecipazione e Conflitto», «OBETS. Revista de Ciencias Sociales» and «Cahiers di Scienze Sociali». His topic is the relationship between social change and transformations of democracy; his empirical researches focus on the political identity of new generations, and deal with migrants' political issues. Among his recent publications: (ed.) Youth for What? New Generations and Social Change, «SocietàMutamentoPolitica. Rivista italiana di sociologia» (Florence 2014); (with L. Raffini and C. Colloca) Volontariato e advocacy in Toscana. Territorio, diritti e cittadinanza (Florence 2014); (ed.) Giovani adesso. Le nuove generazioni a 150 anni dall'Unità d'Italia (Turin 2012); (with C. Colloca and S. Milani, eds.) Città e migranti in Toscana (Florence 2012); (with G.B. Varnier, eds.) Tra Settecento e Novecento: le sfide del cambiamento (Ecig 2012).

LUCA RAFFINI is Fellow Researcher at the University of Genova (Department of Political Sciences). He is member of the editorial board of the scientific journals «SocietàMutamentoPolitica. Rivista italiana di sociologia», and «Partecipazione e Conflitto». Among his field of interest there are the relations between youth and politics; the social and political usage of new media; participation and conflict; mobility and migration. Among his recent publication: La nuova politica. Mobilitazioni, movimenti e conflitti in Italia (with L. Alteri, eds., Napoli 2014); Volontariato e advocacy in Toscana. Territorio, diritti e cittadinanza (with A. Pirni and C. Colloca, Firenze 2014); L'eclissi del ceto medio? Monograpich issue of SocietàMutamentoPolitica (with G. Bettin Lattes, eds., 2013); Manuale di sociologia (with G. Bettin Lattes, eds., Padova 2011).

Recibido: $12 / 05 / 2015$

Aceptado: 20/06/2015 